\title{
Editorial
}

\section{Balancing optimism and criticality in a time of change}

Elaine Hall

Northumbria University, UK

Elaine.Hall@northumbria.ac.uk

It seems only moments ago that I was writing an editorial and - oh yes! - because of the Special Issue on Problematising Assessment, it was in fact only last month. Time is a slippery entity, particularly as we in Higher Education experience more (and more frequent) change alongside significant increases in the demands placed on us. A recent blogpost by Mark Carrigan ${ }^{1}$ highlights the multiple agendas that academics all face: students' learning needs, administration, obtaining research grants and of course 'publish or perish'. On top of all that, readers of the IJCLE engage in clinic, a time-consuming, resource intensive activity, often relegated to the edges of the 'core academic workload'. What on earth are we thinking? Moreover, if it is so hard, why are so many new clinics emerging?

In this issue we have papers that look at clinical developments with a degree of balance - recognising the advantages and positives of clinical work while weighing the costs and complexities. Margaret Castle's paper provides a fascinating insight into a partnership: detailing the pragmatic steps taken to establish the working relationship and reflecting critically on the difficulties of finding a common language 
and structure for teaching and learning. Moreover, she steps back from the process as a whole to engage with the promises of eternal partnerships for law school clinics and assesses whether the hoped-for benefits of time and cost are realised and then, in a final reflexive turn considers whether these benefits were the only or the most important outcomes.

It is always important for us to shift perspective and consider our place in the wider context, so while I agree with Mark Carrigan that these are challenging times for academics in the UK, I also recognise that this is nested within very challenging times for people outside the still relatively protected public sector. Of course, this is the all-important 'why' for many clinicians across the world, providing a service for the public good and developing our students into 'public good' professionals ${ }^{2}$. In countries experiencing significant change and development, the role of clinic is yet to be defined: exploring this, Ai Nhan Ho brings us the historical perspective as well as a detailed analysis of the potential for clinic in Vietnam.

Recent developments in Asia are further explored in Victoria Murray's review of the new book Clinical Legal Education in Asia - Accessing Justice for the Underprivileged, edited by Shuvro Sarker. Here again the balance has to be struck between celebrating new developments and assessing the barriers and threats to sustainability in clinic. As Victoria stresses, colleagues from areas where clinic is

\footnotetext{
${ }^{2}$ Linda East, Rebecca Stokes \& Melanie Walker (2014) Universities, the public good and professional education in the UK, Studies in Higher Education, 39:9, 1617-1633, DOI:10.1080/03075079.2013.801421
} 
longer established but perhaps threatened by austerity could learn from the models of collaboration detailed here.

Finally, we mark the passing of a vital figure in the history of clinic in the UK, Professor Phil Kenny, former Dean of the Law School at Northumbria University. As Jonny Hall's appreciation reveals, you may not know about him but you will have encountered the fruits of his work.

Please let me know of upcoming events in the CLE world for our July 2016 edition. Here is the inevitable reminder about the IJCLE conference with the Association for Canadian Clinical Legal Education (ACCLE) Conference will be hosted by the University of Toronto from 10-12 July. The conference, entitled The Risks and Rewards of Clinic encourages participants to reflect on the balance between risk and reward for all the stakeholders in clinic. We have a fantastic range of papers, seminars and symposia and I'm delighted to announce that we have managed to secure Sarah Buhler and Adrian Evans as keynote speakers.

This will be followed by the International Legal Ethics Conference VII (ILEC VII), which Fordham Law School will host in New York City on July 14-16, 2016 focusing on legal education, ethics, technology, regulation, globalization and rule of law (www.law.fordham.edu/ilec2016). You can submit abstracts until $1^{\text {st }}$ April 2016, so don't miss out! 